May 2012

\title{
Managing work-role transition: from nurse clinician to nurse educator
}

Shirin Rahim

Aga Khan University, shirin.rahim@aku.edu

Munira Prasla

Aga Khan University

Follow this and additional works at: http://ecommons.aku.edu/pakistan_fhs_son

Part of the Nursing Commons

\section{Recommended Citation}

Rahim, S., Prasla, M. (2012). Managing work-role transition: from nurse clinician to nurse educator. i-manager's Journal on Nursing, 2(2), 8-13.

Available at: http://ecommons.aku.edu/pakistan_fhs_son/116 


\title{
ARTICLES
}

\section{MANAGING WORK-ROLE TRANSITION: FROM NURSE CLINICIAN TO NURSE EDUCATOR}

\author{
By \\ SHIRIN RAHIM * \\ MUNIRA PRASLA ** \\ * Lecturer, Aga Khan University School of Nursing, Karachi. \\ ** Instructor, Aga Khan University School of Nursing, Karachi.
}

\begin{abstract}
Change in any aspect of human life is often challenging and requires significant efforts for readjustment from the individual and could result in improving or worsening existing situation. Change in work-role is also a significant event in a person's life. Presentstudy attempts to analyse management of work-role transition from clinical nurse to nurse educator. The study is based on systematic and critical review of articles that appeared in peer-reviewed Journals. Research articles were searched from databases CINAHL, PubMed, Sage, and Science Direct using various combinations of keywords. 20 shortlisted articles were subjected to analysis for common theme of work-role transition and its management with particular reference of nurses' role transition from clinician to educator. Critical analysis of the literature shows that work-role transition is very challenging and require proactive approach of the individual. It also requires institutions to provide effective orientation and mentorship and create welcoming and threat-free environment with well-defined polices and procedures in place. Understanding the process at the individual's level, a health institution for their new employees' can help individual transition smoother resulting in competent nurse educator. Change is very important part of life and change in work-role is no exception. Reflecting on personal experiences shows that transition does not need to be extremely challenging and stressful experience, in fact it is manageable if appropriate steps are taken by individuals and institutions.
\end{abstract}

Keywords: Work-Role Transition, Nurse Educator, New Role Management.

\section{INTRODUCTION}

"The world does not fear new ideas what is fears is the new experience." (D.H. Lawrance). This may be true because every new experience is attached with the process of change or transition and with transition comes the apprehension of failing to adjust to it. Esper (1995) defines transition as a process that occurs when a person changes his perception towards a situation he is in, and attempts to change the situation, this change may either improve or worsen the existing situation. So transition can be healthy or harmful and that is why people fear transitions. But transitions are crucial and inevitable for human growth and bring energy and excitement in life and human beings do undergo many transitions in their lives. One of such transition for which people struggle hard is work role transition which according to Anderson, (2009) is "the human experience associated with entering a new community of practice. It is a dynamic, developmental process to assume the new identity, values, and knowledge base of the new role" (p.203). Like any other profession or work setting, work role transition also frequently takes place in nursing profession. These can be of varying type and at varying stages starting from a graduate nursing student to novice bedside nurse, from novice bed side nurse to an expert clinician and from expert clinician to either advanced clinician or to a novice nurse educator. Whatever is the level, work role transition is not an easy task and requires a lot of struggle and determination to get adjusted in the new role assuming new responsibilities for adjusting in the new role, and emerging with new self. A little mishandling can result in failure in sustaining the new job, and is also a threat to self identity.

Present study attempts to analyse management of workrole transition from clinical nurse to nurse educator. The 


\section{ARTICLES}

main highlights of this paper will be the reasons and significance of the work role transition, phases of transition and its analysis with Duchscher (2008) transition shock framework, factors facilitating and affecting work role transition, and finally strategies to improve the work role transition of a nurse clinician to nurse educator.

\section{Method}

Present study is based on systematic and critical review of articles that appeared in peer-reviewed Journals. Research articles were searched from databases CINAHL, PubMed, Sage, and Science Direct using various combinations of keywords. 20 shortlisted articled were subjected to analysis for common theme of work-role transition and its management with particular reference of nurses' role transition from clinician to educator.

\section{Result and Discussion}

\section{Reasons and Significance of Work Role Transition}

Some studies associate role of a nurse clinician to a nurse educator with greater social prestige and autonomy. Moreover, aspiration to benefit nursing students from rich clinical experience, desire to promote effective and evidence based teaching, flexible schedule are some of the most frequent reasons and for work role transition of nurse clinician to nurse educator. (Culleiton \& Shellenbarger, 2007; Esper, 1995; Mcdoland, 2010).

Although this work-role transitions may be attractive for most of the clinicians, it also becomes overwhelming when it does not turn out to be healthy, which, according to Anderson (2009), "a healthy transition includes a sense of personal well-being, mastery of new knowledge and skills, confidence in the match of the new role, return of confidence and comfort, and a sense of competence in the new role." (p.207). It is this point of work role transition that it becomes a significant issue for the individual nurse and also for the organization to be handled effectively. Scott and Jaffe(2004) quote a study done by Homes and Rahe in saying that "people who were suffering serious illness or were involved in accidents had experienced a significant transition in their lives, lately. (p. 7)"

It was unclear through literature review that how many times work role transitions became difficult to handle and caused any significant event in nurses' professional and personal lives and also in the organizations they work. However, several studies clearly show that work role transition requires physical, emotional, socio-cultural and developmental adjustment in new setting. According to Infante (1986) "Becoming a nurse educator is not a matter of adding the role of educator to that of the nurse. It requires a change in knowledge, skills, behaviors, and values to prepare for the new assimilated role (p. 94). "Anderson (2009), in his naturalistic inquiry on same issue has come up with the metaphor of "mermaid swimming in the sea of academia" for the expert nurse clinician who is now a transitioned novice nurse educator. Anderson (2009) further define the subtheme coming out from data analysis one of which is "drowning". This happens due to feelings of overwhelming, as nurse educator in her transition has to "leave the comfort zone, fit in and establish new relationship, learn and unlearn, face reality and questioning" (Anderson 2009, p.205)and when these are not fulfilled the novice nurse educator feels like drowning.

When these adjustments are not achieved, problems in transition becomes an individual and organizational issue. Mangers and leaders of an organization can help novice nurse educators coming from other settings to manage their work role transition effectively. (Anderson, 2009; MacNeil, 1997).

\section{Phases of Work Role Transition}

Three phases of work role transition presented by Schlossberg (1984) are preoccupation, struggling, and integration. Schlossberg (1984) had attempted to explain these phases in relation to work role transition of nurse clinician to nurse educator.

First is the preoccupation phase in which the individual is very much eager to enter in to the new role of nurse educator and remain busy in thinking how she will make difference at school of nursing with her existing experience and knowledge. This is the stage where the nurse clinician is so much preoccupied with the transition taking place that all she thinks, sees and listens about the role of educator is good and only good. She can only foresee opportunities and no challenges are sensed at this stage.

Next is the struggling phase (transition shock). This is the 


\section{ARTICLES}

phase when conflicts between past and present worlds of experiences occur. These conflicts which according to Diekelmann (2004) and Infanate (1986) are mostly due to inadequate system in the school or colleges of nursing to facilitate the adjustment of novice nurse educator into their new role. Here the nurse clinician feels herself to be too new, and too inexperience as compared to her previous work setting where she was the most skilled and most practiced nurse, with every one taking her expert opinion when in doubt. This is the stage where newly transitioned nurse educator faces the real world of education with feelings of inadequacy, guilt, embarrassment, and inability to meet others' expectations. Now she realizes that the new world is also has its own challenges and work role transition is not just changing the campus a lot more change is requires which includes working environment, roles, responsibility, expectation, work load etc. Hence there is too much either to change or to adapt in a in minimum time to get adjusted to this new role fast. It is this time when the transition can be proved to be either successful or unsuccessful.

The last one is the integration phase, where according to Schlossberg (1984) "The individual can experience renewal, acceptance, or deterioration." (p.61). This is the stage where, Schlossberg (1984) explains, the result of the transition appears and the nurse rekindles herself either by accepting and getting fully adjusted in the new role or by rejecting the new role and going back to the old one or in the worst case rejecting to work at all.

Exploring The Phase of Transition Shock in Light of A Framework

After going through the phases of transition and relating it with the work role transition of a nurse clinician to nurse educator, it is understood that the most vulnerable stage, among the three, is the one in which realities are confronted and transition shock is encountered; whether the transition will turn out to be successful or not mostly depends on passing this stage. To be able to qualify in this crucial phase it is essential to get familiar with what actually happens in this stage and how one can manage to come out of it successfully.

Duchscher (2008), defines transition shock as:
The experience of moving from the known role to the relatively less familiar role. Important to this experience is the apparent contrast between the relationships, roles, responsibilities, knowledge and performance expectation required within the more familiar practice setting environment to those required in the academic setting. (p.3)

Duchscher (2008), proposed a Transition Shock Framework in which characteristics of transition shock is explained in four steps.

In First step individual feels the contrast between the new and the old work settings in four areas that are- roles, responsibilities, relationship, and knowledge. In next step this contrast leads to the feelings of confusion, doubt, loss, and disorientation. At last all these contrast and feelings jumble in form of the challenges which need to be overcome for a successful transition to happen. These challenges can be felt in physical, intellectual, emotional and socio-developmental aspects of ones life.

\section{Strategies to Facilitate Work Role Transition}

Based on literature review here are some strategies to manage the work role transition.

\section{Strategies at Individual Level}

Nurse clinicians who are planning to have work role transition from nurse clinician to nurse educators must take initiatives, strive hard and explore ways themselves to get adjusted to the new environment as soon as possible. They should know the process of transition and the basics of their own organization and ways of getting adjusted to new roles and responsibility, knowledge and relationships. (Culleiton \& schellenbarger 2007). This can be achieved by following some tips given by Bellack (2003), who suggests novice nurse educators to:

Learn about the school and new colleagues early. Learn the institution's and school's organizational structure and reporting lines. Obtain and carefully review the institution's or school's catalog, faculty handbook, student handbook, clinical rotation handbook, and other core documents. Seek early and ongoing help and support from immediate supervisor. Seek out approachable faculty colleagues and learn. 


\section{ARTICLES}

Explore resources the institution or school makes available to new faculty and take advantage of them. Find ways to maintain balance between professional commitments and personal life. Do not rush into tasks. Engage in reflection and mindfulness before beginning any task. (P.384).

\section{Strategies at Organizational Level}

Review of the literature also suggests that mentorship and orientation program, welcoming culture of organizations, and opportunities for new nurse educators for knowledge enhancement are the best strategies at organizational level to help new nurse educators to adjust successfully in the new role and complete their work role transitions successfully. (Hessler \& Ritchie, 2006; Kay, 2009; Siler \& Kleiner, 2001). Boice (2000) indicates that, "One fact stands out in my 20 years of studying new faculty: Almost all the failures... of....new hires owed to misunderstandings about effective ways of working and socializing" (p. 1). So schools and colleges of nursing should develop effective mentorship and orientation programme for new nurse educators and others to help them succeed in their transition

\section{Mentoring}

To start with mentorship, Snelson, Martsolf, Dieckman, Anaya, Cartechine, Miller, Roche and Shaffer (2002), have developed a mentorship programme with the porpose of "linking experienced faculty with new or less experienced teachers to provide assistance in adapting to the role of educator and promoting socialization to the Kent State University environment.(p.656)." The programme participants identified it very useful and based on their responses Snelson et al (2002, p. 659) have proposed some strategies to be included in useful mentor programme. The strategies are

- Information on accessing secretarial support

- Identifying and locating teaching resources

- locating departments for specific information

- Observing an experienced faculty member at a clinical site

- Providing overview of the undergraduate and graduate curricula
- Writing for publication, and

- Identifying methods to document student behaviors.

Smith and Zsohar (2007) warn organizations for selecting right person for the job. According to them "A mentor possesses the characteristics of generosity, competence, self-confidence, and a commitment to the mentor relationship, along with faculty camaraderie (p. 185)."

Smith and Zsohar (2007) also suggest organizations to provide mentor training to the faculty who would be mentors for new educators. This training should include teaching techniques and teaching learning principles for adults. If Organizations and schools try these strategies it can benefit new nurse educators to have a successful and smooth work role transition.

\section{Orientation}

Furthermore the literature suggests that one way for smoothening the work role transition of nurse clinician to nurse educator is having an effective orientation programme before starting job actually (Genrich \& Pappas, 1997; the Morin \& Ashton, 2004). The focus of orientation should be development of nurse educators in terms of giving them training for the new role so that the new nurse educator knows what role to be fulfilled and how. Genrich, and Pappas, (1997) further say on orientation that: This requires that the new employee be introduced to their specific job, department, and coworkers; on-the job expectations; available resources; and the skills needed for job performance. A well-designed orientation program identifies the unique educational needs of each orientee and provides a mechanism for on-the-job training to address those needs. (p.85)

\section{Welcoming Environment}

One more strategy that a school of nursing must adopt for helping new nurse educators to get adjusted quickly is to ensure friendly working environment at all levels of authority. Dempsey (2007) found in her study on transition from clinician to educators in Irish nurses that collegial support was ranked highly important and beneficial during transition. One of her participant said that (as she quotes)

"The one thing that really helped was all my colleagues were around me. They came up to me and made me 


\section{ARTICLES}

understand that they were there and I could just go and ask them for help and that was good. . . the support of the people around you is really essential. (p.6)"

Same is for supervisors and directors of the school. Their support always motivates and raises energy to compete with circumstances and witness victory. One more participant 's response from Dempsey (2007) study very well indicates the importance of directors' support by saying that

"Where I work, the Head of Department there has lots of experience, she was very helpful in directing me and there's definitely an open door policy there in that if you had any difficulties you could just walk in (p.6)."

\section{Strategy at Policy Level}

At policy level it is suggested that the criteria for hiring nurse educators should be revised starting from minimum master's degree with at least 5-7 years of clinical experience, as this according to the authors experience will help both the individual nurse educator and the school of nursing during and after transition periods. Most of the challenges of transition will be taken care of by higher education and longer experience, and will benefit nursing students also.

Next policy makers should make sure that all of the above strategies are applied in all the schools or colleges of nursing so as to make the transition process as contented, and satisfying as possible. This will help novice nurse educators to grow into competent teachers who can produce better generation of nursing students and ultimately make their contribution towards organizations growth and the growth of the entire profession.

\section{Conclusion}

Transitions are important part of one's life, without which human growth is stagnant. A human being throughout his life undergoes many transitions, one of which is work role transition in which a person decides to change his older work setting with another newer one. Based on the perception of the two settings, and the result of this transition will depend upon the success of transition process that takes place.

This paper focused on work role transition from nurse clinician to nurse educator. It attempted to highlight the significance and phases of work role transition, elaborated on the phase of transition shock and proposed strategies in light of literature on work role transition from nurse clinician to nurse educator. Transition shock is the most important phase of transition process which brings conflicts, negative feelings and many challenges with it, but if this phase is managed properly it can result in greater personal and job satisfaction of nurse educators and consequently have positive impact on an organizational credibility and productivity, whereas any mismanagement in this phase may end up in failure and weakening of the individual in such a way that one may decide to either go back to previous work setting or in the worst case may leave the organization and even the profession.

\section{References}

[1]. Anderson, J.K. (2009). The work-role transition of expert clinician to novice academic educator. The Journal of Nursing Education. 4, (4), 203-208.

[2]. Bellack, J.P. (2003). Advice for New (and Seasoned) Faculty. Journal of Nursing Education 42, (9), 383-384.

[3]. Boice, R. (2000). Advice for new faculty members. Needha Heights, MA: Allyn and Bacon.

[4]. Culleiton, L.A., \& Shellenbarger, T. (2007). Transition of a bedside clinician to a nurse educator. MEDSURG Nursing, 16, (4). 253-257.

[5]. Dempsey, L. M. (2007). The experiences of Irish nurse lecturer's role transition from clinician to educator. International Journal of Nursing Education Scholarship, 4, (1), 1-12.

[6]. Diekelmann, N. (2004). Experienced practitioners as new faculty: new pedagogies and new possibilities. Journal of Nursing Education. 43, (3), 101-103.

[7]. Duchscher, J.B. (2008). Transition shock: the initial stage of role adaptation for newly graduated Registered Nurses. Journal of Advanced Nursing. 1-11.

[8]. Esper, P. S. (1995). Facing transition--nurse clinician to nurse educator. The Journal of Nursing Education, 34, (2), 89-91.

[9]. Genrich, S.J., \& Pappa, S.A. (1997). Retooling Faculty Orientation. Journal of Professional Nursing, 13, (2), 84-89. 


\section{ARTICLES}

[10]. Hessler, K., \& Ritchie, H. (2006). Recruitment and Retention of Novice Faculty. Journal of Nursing Education, 45, (5). 150-153.

[11]. Infante, N.S. (1986). The conflicting roles of nurse and nurse educator. Nursing Outlook, 34, (2), 94-96.

[12]. Kay, L. (2009). Still a midwife? The transition from clinician to educator. The Practising Midwife, 12, (8) of Advance Nursing. 1-11.

[13]. MacNeil, M. (1997). From nurse to teacher: recognizing a status passage. Journal of Advanced Nursing. 25, 634-642.

[14]. McDonald. P.J. (2010). Transitioning from Clinical Practice to Nursing Faculty: Lessons Learned. Journal of Nursing Education, 49, (3). 126-131.

[15]. Morin, K.H., \& Ashton, K.C. (2004). Research on Faculty Orientation Programs: Guidelines and Directions for Nurse Educators. Journal of Professional Nursing, 20, (4). 239-250
[16]. Schlossberg, N.K. (1984). Counseling adults in transition: Linking practice with theory. Springer :NewYork.

[17]. Scott, C.D., \& Jaffe, D.T. (2004). Managing personal change: Moving through personal transition. Retrieved from http://www.axzopress.com/downloads/pdf/ 1560526807 pv.pdf.

[18]. Siler, B.B., \& Kleiner, C. (2001). Novice faculty: encountering expectations in academia. Journal of Nursing Education. 40, (9). 397-403.

[19]. Smith, J.A., \& Zsohar, H. (2007). Essentials of neophyte mentorship in relation to the faculty shortage. Journal of Nursing Education, 46, (4), 184-186.

[20]. Snelson, M.C., Martsolf, D.S., Dieckman, B.C., Anaya, E.R., Kathy A. Cartechine, K.A., Miller, B., Roche, M. \& Shaffer, J. (2002). Caring as a theoretical perspective for a nursing faculty mentoring program. Nurse Education Today. 22, 654-660.

\section{ABOUT THE AUTHORS}

Shirin Rahim is currently working as a Lecturer in Aga Khan University School of Nursing at Karachi.

Munira Prasla is currently working as an Instructor in Aga Khan University School of Nursing at Karachi. 